\title{
Atividades lúdico-educativas sobre Infecções Sexualmente Transmissíveis: uma proposta de Divulgação Científica no ambiente escolar
}

\author{
Playful-educational activities on Sexually Transmitted Infections: Scientific Dissemination proposal \\ in the school environment
}

Actividades lúdico-educativas en Infecciones de Transmisión Sexual: una propuesta de Difusión

Científica en el ámbito escolar

\author{
Ariele da Silva Martins \\ ORCID: https://orcid.org/0000-0002-1163-7803 \\ Universidade Federal do Estado do Rio de Janeiro, Brasil \\ E-mail: arielemartins2@edu.unirio.br \\ Marcella Larrate da Silva \\ ORCID: https://orcid.org/0000-0002-2515-7130 \\ Universidade Federal do Estado do Rio de Janeiro, Brasil \\ E-mail: marcellalarrate@edu.unirio.br \\ Thamyris Figueiredo do Amaral \\ ORCID: https://orcid.org/0000-0001-9453-1555 \\ Universidade Federal do Estado do Rio de Janeiro, Brasil \\ E-mail: thamyrisamaral@edu.unirio.br \\ Mariana Soares da Silva Peixoto Belo \\ ORCID: https://orcid.org/0000-0001-9666-284X \\ Universidade Federal do Estado do Rio de Janeiro, Brasil \\ E-mail: mariana.belo@unirio.br \\ Bianca Ramos Marins Silva \\ ORCID: https://orcid.org/0000-0002-2664-9794 \\ Universidade Federal do Estado do Rio de Janeiro, Brasil \\ E-mail: bianca.silva@unirio.br \\ Patrícia Cristina dos Santos Costa \\ ORCID: https://orcid.org/0000-0003-0111-6980 \\ Universidade Federal do Estado do Rio de Janeiro, Brasil \\ E-mail: patricia.costa@unirio.br
}

\begin{abstract}
Resumo
Divulgação Científica (DC) é um método de difusão do conhecimento científico-acadêmico cujo objetivo é democratizar o acesso à informação e estimular o desenvolvimento de senso crítico, atingindo diferentes públicos. A utilização de práticas lúdico-educativas como método de divulgação faz-se necessária para um aprendizado mais dinâmico e com maior desenvolvimento cognitivo. Reforça ainda as instituições de ensino como importantes promotoras de ações educativas, especialmente em saúde. Sabendo que os adolescentes estão entre os grupos mais vulneráveis e possuem defasagem de conhecimento básico quanto às Infecções Sexualmente Transmissíveis (IST), a adoção de intervenções mais efetivas acerca do tema é crucial. Assim, com esse trabalho, objetiva-se propor estratégias de DC em espaços escolares através de atividades lúdico-educativas sobre IST como ferramenta pedagógica e promotora da saúde. Esta proposta de divulgação científica é composta por estratégias de ensino, diferentes do modelo expositivo tradicional, tais como a promoção de conhecimento por meio de informações básicas e preventivas sobre essas infecções e seus impactos na saúde; ações interativas através de jogos de perguntas e respostas intitulados "Jogo de Tabuleiro Humano", "Quiz Torta na Cara" e "Ida ao Posto de Saúde"; e divulgação das unidades locais de Atenção Primária à Saúde. Essas atividades lúdicas são relevantes por estimularem a participação e trabalho em equipe dos estudantes envolvidos, além de favorecerem ao processo de ensino-aprendizagem mais atrativo e criativo, questões fundamentais para a prática de ações promotoras da saúde no ambiente escolar.
\end{abstract}

Palavras-chave: Comunicação e divulgação científica; Infecções Sexualmente Transmissíveis; Atividades educativas; Adolescentes.

\section{Abstract}

Scientific Dissemination (SD) is a method for disseminating scientific-academic knowledge whose objective is to democratize access to information and encourage the development of critical thinking, reaching different publics. Ludiceducational practices application as dissemination method is necessary for a more dynamic learning and greater cognitive development. Besides that, educational institutions are seen as important promoters of educational actions, 
especially in the health area. Knowing that adolescents are among the most vulnerable groups and have a basic knowledge deficiency about Sexually Transmitted Infections (STIs), the adoption of more effective interventions on the subject is crucial. Thus, with this work, the objective is to propose SD strategies in school spaces through playfuleducational activities about IST as a pedagogical tool and health promoter. This proposal for Scientific Dissemination is composed of teaching strategies, different from the traditional expository model are highlighted, such as the promotion of knowledge through basic and preventive information about these infections and their impacts on health; interactive actions through quiz games entitled "Jogo de Tabuleiro Humano", "Quiz Torta na Cara" and "Ida ao Posto de Saúde"; and dissemination of local Primary Health Care units. These ludic activities are relevant because they encourage the participation and teamwork of the students involved, in addition to favoring a more attractive and creative teaching-learning process, fundamental issues for the practice of health-promoting actions in the school environment. Keywords: Communication and scientific dissemination; Sexually Transmitted Infections; Educational activities; Adolescents.

\section{Resumen}

La Divulgación Científica (DC) es un método de difusión del conocimiento científico-académico cuyo objetivo es democratizar el acceso a la información y estimular el desarrollo del pensamiento crítico, alcanzando diferentes públicos. El uso de prácticas lúdico-educativas como método de difusión es necesario para un aprendizaje más dinámico y con mayor desarrollo cognitivo. También refuerza a las instituciones educativas como importantes promotoras de acciones educativas, especialmente en salud. Teniendo en cuenta que los adolescentes se encuentran entre los grupos más vulnerables y carecen de conocimientos básicos sobre las Infecciones de Transmisión Sexual (ITS), la adopción de intervenciones más efectivas sobre el tema es crucial. Así, con este trabajo se tiene como objetivo proponer estrategias de DC en los espacios escolares a través de actividades lúdico-educativas sobre las ITS como herramienta pedagógica y promotora de salud. Esta propuesta de divulgación científica se compone de estrategias didácticas, distintas al modelo expositivo tradicional, como la promoción del conocimiento a través de información básica y preventiva sobre estas infecciones y sus impactos en la salud; acciones interactivas a través de juegos de preguntas y respuestas titulados "Jogo de Tabuleiro Humano", "Quiz Torta na Cara" y "Ida ao Posto de Saúde"; y difusión de las unidades locales de Atención Primaria de Salud. Estas actividades lúdicas son relevantes porque fomentan la participación y el trabajo en equipo de los estudiantes involucrados, además de favorecer un proceso de enseñanza-aprendizaje más atractivo y creativo, cuestiones fundamentales para la práctica de acciones promotoras de salud en el ambiente escolar. Palabras clave: Comunicación y divulgación científica; Infecciones de Transmisión Sexual; Actividades educativas; Adolescentes.

\section{Introdução}

Divulgação Científica (DC) refere-se a um método de difusão do conhecimento científico-acadêmico que objetiva democratizar o acesso à informação e alcançar indivíduos, de todas as faixas etárias, através do uso de uma linguagem coloquial, a fim de facilitar a fluidez da comunicação com o público leigo (Albagli, 1996; Bueno, 1984 conforme citado em Miranda et al., 2020). Mídias sociais, textos, atividades e jogos lúdico-educativos são frequentemente utilizados para o ensino formal e nãoformal, impulsionando o estudante a participar de práticas escolares (Schwanke \& Melo, 2002; Schwanke \& Silva, 2004; Rodrigues et al., 2005 conforme citado em Melo et al., 2007). Além disso, dinâmicas com aspecto lúdico favorecem a cooperação, aproximação, sociabilização, promoção de conhecimento e geração de senso crítico, visando uma melhor vivência em comunidade (Pedroso, 2009).

As instituições escolares são frequentadas por públicos de diferentes classes sociais, faixas etárias, etnias e gêneros durante um extenso período, tendo como responsabilidade a assistência à aspectos psicológicos e sociais, bem como o incentivo à educação e conhecimento diversos, a fim de promover interações e alterações comportamentais positivas a esses indivíduos (Almeida et al., 2017; Sousa, 2020). De forma mais extensiva, o modelo tradicional de ensino é caracterizado pela aplicação de conceitos, sem considerar as peculiaridades envolvidas, a partir da verbalização do docente e memorização e aceitação do discente, restringindo o conhecimento cognitivo à sala de aula e/ou a atividades expositivas pouco interativas. Embora esse método possua baixo custo e a propagação de conhecimento seja feita em grupo e com ampla abrangência de conteúdo, sua avaliação metodológica não possibilita a percepção intrínseca do conhecimento adquirido pelo estudante (Souza et al., 2014). Assim, a utilização desse modelo estabelece aprendizado mecânico capaz de prejudicar a compreensão do conteúdo e o interesse, com enfoque maior na quantidade de temáticas abordadas quando comparado ao desenvolvimento de senso crítico pelo estudante 
(Pereira et al., 2020). Com os avanços tecnológicos e a defasagem do modelo tradicional de ensino, baseado na transmissão de conhecimento de maneira expositiva, faz-se necessária a adaptação metodológica pautada em práticas lúdicas e interativas, conferindo um aprendizado mais dinâmico e com maior desenvolvimento cognitivo (Pereira et al. 2020).

Por outro lado, a metodologia ativa reconhece as singularidades do indivíduo, aplicando técnicas adequadas para a promoção do conhecimento e elaborando estratégias, por meio do exercício, que viabilizam a interação recíproca entre docente e discente. Através dos inúmeros dispositivos para a realização desse método, é possível individualizar e direcionar as demandas de conteúdo, e com isso, promover uma avaliação mais efetiva do conhecimento. Contudo, essa metodologia requer maior investimento de recursos e demanda atividades em pequenos grupos (Souza et al., 2014).

Desta forma, práticas pedagógicas inovadoras, tais como as desenvolvidas por instituições de ensino superior, estimulam o rompimento das estruturas do modelo tradicional de ensino, ultrapassam os limites técnicos e contribuem para formação de profissionais competentes, éticos, críticos e reflexivos; além de estabelecer corresponsabilidade no processo de ensinoaprendizagem (Cyrino \& Toralles-Pereira, 2004; Mitre et al., 2008; Souza et al., 2014). Por isso, novas abordagens educacionais, como as atividades lúdicas, vêm sendo implementadas de modo a garantir um ensino mais ativo, participativo, motivacional, integrado e construtivo, que, quando combinado ao modelo expositivo, estimulam o estudante na construção do conhecimento e enriquece este processo (Pereira et al., 2020).

Além do influente papel das instituições de ensino na promoção de ações educativas em saúde, junto a elas, Organizações Governamentais (OG) e Não-Governamentais (ONG) têm desenvolvido práticas pedagógicas de maneira efetiva com diferentes grupos populacionais, em especial os jovens (Cruz, 2006). Destaca-se o Programa Saúde na Escola (PSE), desenvolvido pelo Governo Federal e realizado em parceria com a Atenção Primária à Saúde (APS) e as Secretarias Municipais de Educação (Ramos et al., 2020).

O PSE direciona-se a escolares e têm como proposta atividades envolvendo: promoção de atividade física; educação alimentar e nutricional; promoção da cultura de paz e dos direitos humanos; prevenção de violências, acidentes, doenças negligenciadas, uso de álcool e outras drogas; saúde bucal, auditiva, ocular, sexual e reprodutiva; bem como prevenção do HIV/IST (Ministério da Saúde [BR], 2021). Outros programas, estratégias e ações em saúde são desenvolvidas pelo Governo Federal em diversas áreas, tais como: Escolas Promotoras da Saúde, Programa Mais Educação, Estratégia Saúde da Família, Promoção do Aleitamento Materno, Programa de Diabetes e Hipertensão, Programa Academia da Saúde e Vigilância Alimentar e Nutricional, (Cruz, 2006; Graciano et al., 2015).

Sabe-se que questões relacionadas à sexualidade e saúde reprodutiva são temas elencados nas políticas públicas, contudo, ainda observa-se pouca adesão do público jovem, o que demonstra a necessidade de intervenções mais efetivas (Carloto \& Damião, 2018). Somado a isso, o baixo investimento e os tabus envolvidos em temas relacionados à educação sexual são capazes de prejudicar a comunicação em saúde com os jovens (Organização Mundial da Saúde, 2016; Fernandes, 2020).

A sexualidade incorpora, além de aspectos biológicos, questões estruturais individuais, sociais, psíquicas, culturais e históricas que sustentam crenças e valores propagados pela população; de caráter moral, religioso e cultural (Fernandes, 2020). Neste contexto, também pode estar associada à educação recebida e à ausência de informações sobre o assunto no âmbito familiar e nas escolas (Freire et al., 2016; Santos et al., 2019).

Logo, a escola como instituição social possui um papel fundamental nas discussões relacionadas a essa temática, visto que trata-se de um ambiente acolhedor que viabiliza a inclusão, equidade, enfrentamento de preconceitos e discriminações e reconhece a pluralidade e as individualidades (Fernandes, 2020).

Dessa forma, a adoção de estratégias como a educação em saúde por meio da divulgação científica, possibilita abordar temas relevantes como as Infecções Sexualmente Transmissíveis (IST), suas práticas de risco e a desconstrução de pré-conceitos; 
e estimular a reflexão para construção de saberes junto à comunidade escolar (Ahari et al., 2020; Organização Mundial da Saúde, 2019).

As IST são causadas por bactérias, vírus ou por outros microrganismos, podendo ser curáveis ou não curáveis e apresentar períodos sintomáticos ou permanecer assintomáticas ao longo da vida (Ministério da Saúde [BR], 2021). As taxas de incidência e prevalência associadas a outros indicadores vêm crescendo gradativamente ao longo da década, contabilizando mais de 1.000.000 de casos de IST curáveis no mundo; atingindo principalmente indivíduos de 15 a 49 anos e sendo mais de $40 \%$ referentes a novas infecções no Brasil (Ministério da Saúde [BR], 2017; Costa et al., 2019; Imprensa, Criação \& Marketing, 2021). Ademais, é importante ressaltar que essas doenças influenciam negativamente aspectos psicossociais e econômicos de grande parte da sociedade e, como consequência, impactam a saúde pública (Fernandes et al., 2000; Doreto \& Vieira, 2007).

Os adolescentes estão entre os grupos mais vulneráveis pois muitas vezes iniciam sua vida sexual de forma prematura e inapropriada, o que pode justificar o aumento de 53\% em suas taxas de infecção no ano de 2019 quando comparado a períodos anteriores (Amoras et al., 2015; Ministério da Saúde [BR], 2017; Costa et al., 2019). De acordo com Costa e colaboradores (2019) e Shannon e Klausner (2018), a dificuldade de acesso à informação em saúde, questões relacionadas ao gênero, relações familiares conturbadas e/ou negligenciadas, marginalização social e geográfica e o baixo nível de escolaridade podem favorecer o aumento dos índices de exposição às IST e reduzir as chances de diagnóstico e tratamento quando comparado ao público adulto.

Estudos realizados constataram que grande parte dos adolescentes e jovens possuem defasagem de conhecimento básico nesta temática. Castro e colaboradores (2016) observaram que $81 \%$ desta população apresentou dúvidas referentes a essas infecções, enquanto Doreto e Vieira (2007) verificaram que apenas parte desses agravos eram conhecidos - como a AIDS, Sífilis, Herpes genital, Gonorreia e HPV. Os boletins epidemiológicos referentes ao ano de 2020 e publicados pelo Ministério da Saúde, por sua vez, evidenciaram que indivíduos com grau de escolaridade entre a $5^{\mathrm{a}}$ e a $8^{\mathrm{a}}$ série incompletas representam o segundo maior número de casos de Hepatites B e C e o terceiro grupo em casos de Sífilis e HIV (Ministério da Saúde [BR], 2020).

Assim sendo, este artigo tem como objetivo propor estratégias de divulgação científica em espaços escolares através de atividades lúdico-educativas sobre as IST como ferramenta pedagógica e promotora da saúde.

\section{Metodologia}

Para a construção da proposta desta atividade foi realizado levantamento bibliográfico utilizando as bases de dados Google Acadêmico, Periódicos Capes e PubMed. Como estratégia de busca foram utilizados os descritores "Divulgação Científica”, "Infecções Sexualmente Transmissiveis", “IST”, "Jogos Educativos”, “Atividades Lúdicas” e "Adolescentes”; e selecionados artigos publicados nos últimos 10 anos.

A utilização de jogos como estratégia mediadora para a construção do conhecimento em saúde individual e coletiva tem sido alvo de muitos estudos no âmbito acadêmico (Meirelles et al., 2017). Jogos como tabuleiros, perguntas e respostas, videogames e os demais são apresentados como ferramentas lúdicas alternativas ao modelo expositivo tradicional normalmente desenvolvido em sala de aula, conforme apontam os estudos de Casseb et al. (2020), Andrade et al. (2019) e Vasconcellos et al. (2017) que foram balizadores para este trabalho.

Dessa forma, a proposta de divulgação científica intitulada "IST: quem se liga, não vacila!” buscou identificação com o público adolescente através de linguagem mais apropriada à realidade desta faixa etária. As atividades lúdico-educativas foram pensadas de modo a serem acessíveis, reutilizáveis, de baixo custo e direcionadas a espaços escolares com discentes do segundo segmento do ensino fundamental.

A proposta fundamenta-se em uma coletânea de atividades estruturadas em três etapas: (I) Promoção de conhecimento através da implementação de técnicas visando fornecer informações básicas e preventivas sobre as IST e seus impactos sobre a 
saúde; distribuição de panfletos informativos e exposição de métodos preventivos; (II) Desenvolvimento de ações interativas por meio da produção de jogos e outras atividades pedagógicas, objetivando o interesse dos estudantes para o tema; (III) Divulgação das Unidades de Atenção Primária à Saúde no território.

A referida proposta resulta da avaliação de componente curricular obrigatório do curso de graduação em Biomedicina da Universidade Federal do Estado do Rio de Janeiro (UNIRIO) que aborda a área da saúde coletiva.

\section{Resultados e Discussão}

As etapas sequenciais da proposta “IST: quem se liga, não vacila!” encontram-se ilustradas na Figura 1 e foram organizadas da seguinte forma: (1) roda de conversa; (2) disponibilização de panfletos informativos; (3) jogo lúdico-educativo intitulado "Jogo de Tabuleiro Humano"; (4) jogo lúdico-educativo intitulado "Quiz Torta na Cara”; (5) jogo lúdico-educativo intitulado "Ida ao Posto de Saúde"; (6) divulgação das Unidades de Atenção Primária à Saúde; (7) premiação de participação e da turma com mais acertos durante a elaboração das atividades e (8) avaliação da aprendizagem dos alunos participantes.

Figura 1: Representação ilustrativa das atividades sequenciais envolvidas na ação "IST: Quem se liga, não vacila!”.

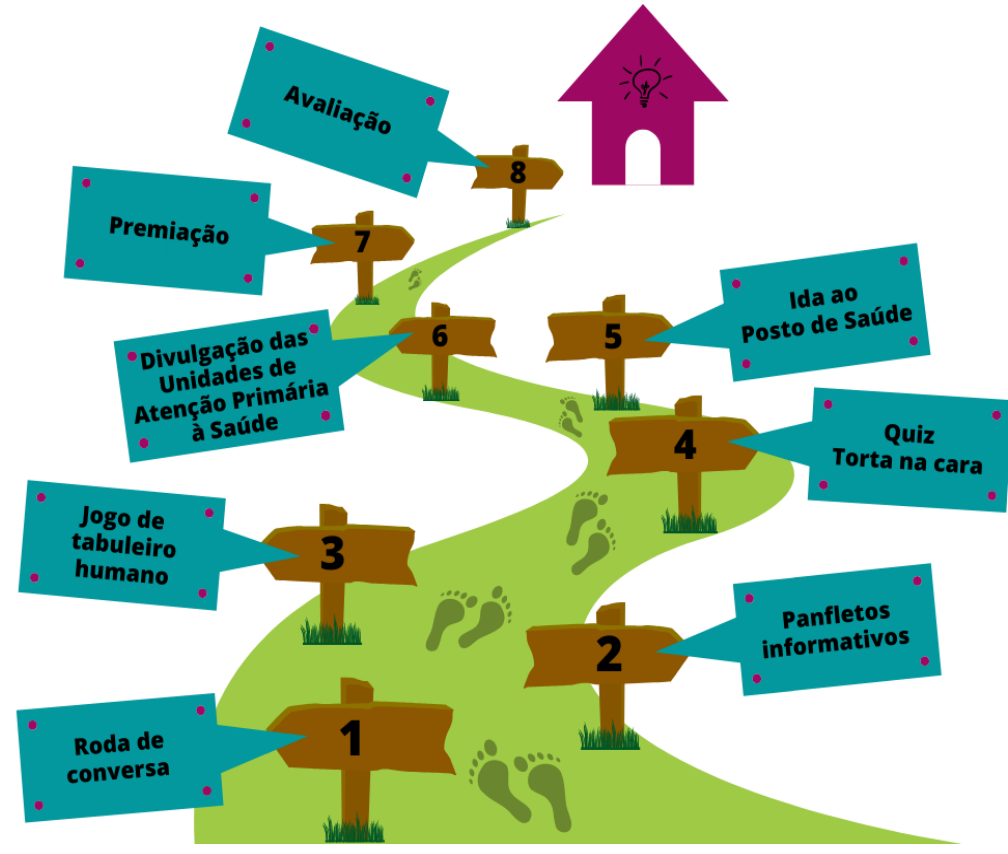

Fonte: Autores (2021).

\section{Promoção de conhecimento sobre as IST e seus impactos sobre a saúde da mulher e da criança}

Inicialmente, propõe-se a promoção de conhecimento com a apresentação de informações básicas e preventivas sobre as IST e seus impactos sobre a saúde da mulher e da criança organizada em dois momentos: (1) roda de conversa sobre a temática em questão e (2) distribuição de panfletos informativos e exposição de métodos preventivos como camisinha masculina e feminina.

Estas atividades objetivam problematizar a conceituação das IST, as infecções existentes, formas de transmissão, sintomatologia, diagnóstico, tratamento e profilaxia; e ainda apresentar e discutir os métodos contraceptivos. A utilização de rodas de conversa como estratégia adaptada de palestras se justifica para apresentação do conteúdo informativo em curto espaço de tempo (Figueiredo et al., 2001; Santos et al., 2020). Em associação, o uso de panfletos se deu para apresentar as informações de maneira resumida, tornando-as mais acessíveis. 
Research, Society and Development, v. 11, n. 2, e24711225598, 2022

(CC BY 4.0) | ISSN 2525-3409 | DOI: http://dx.doi.org/10.33448/rsd-v11i2.25598

Nas Figuras 2 e 3 apresentamos o panfleto explicativo desenvolvido contendo (1) informações gerais sobre as IST, tais como sua definição, classificação, transmissão, diagnóstico e tratamento; e informações específicas e diferenciais sobre as infecções mais recorrentes; (2) um $Q R$ code elaborado para georreferenciar as Unidades de Atenção Primária de Saúde e para melhor orientar os adolescentes sobre os locais de atendimento e (3) um aplicativo relacionado ao tema e disponível na Google Play.

Figura 2: Panfleto explicativo elaborado como produto da disciplina (anverso).

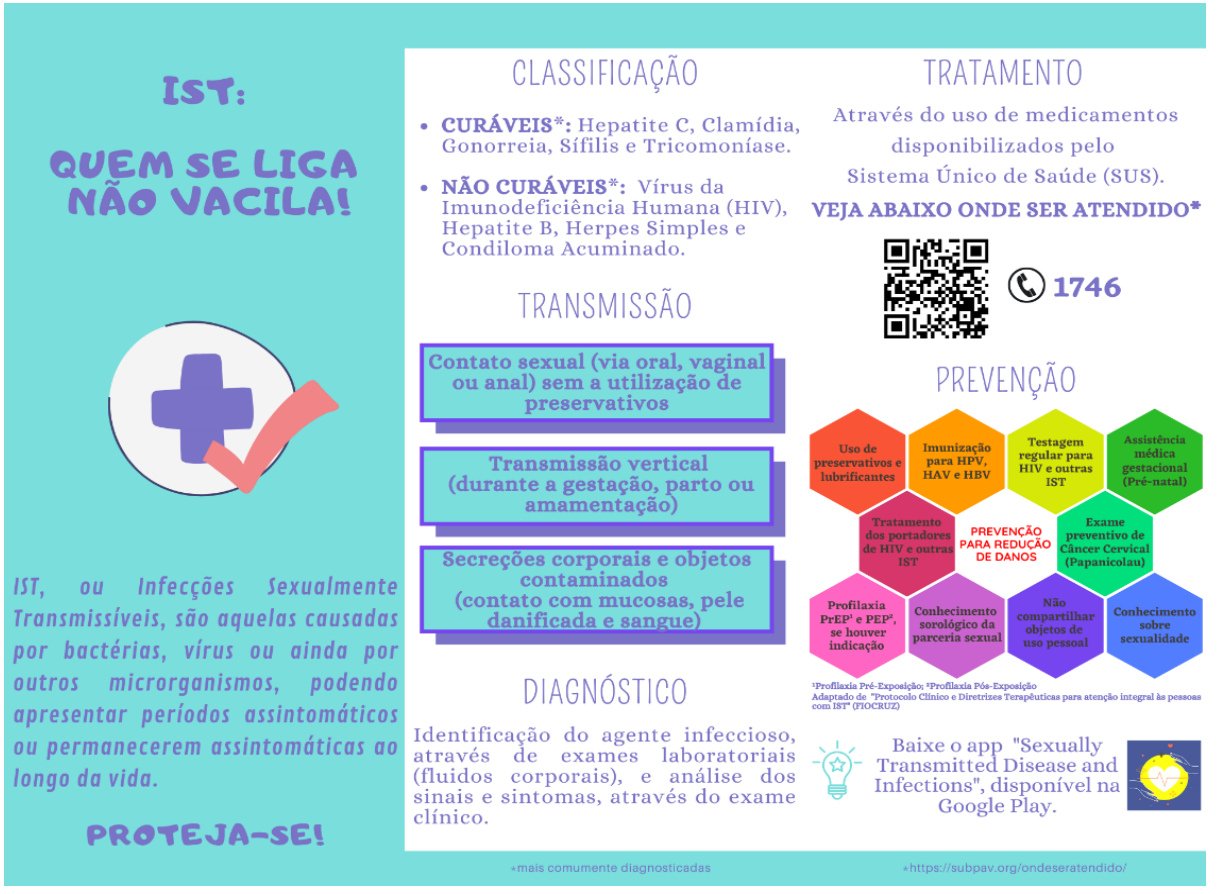

Fonte: Autores (2021).

Figura 3: Panfleto explicativo elaborado como produto da disciplina (verso).

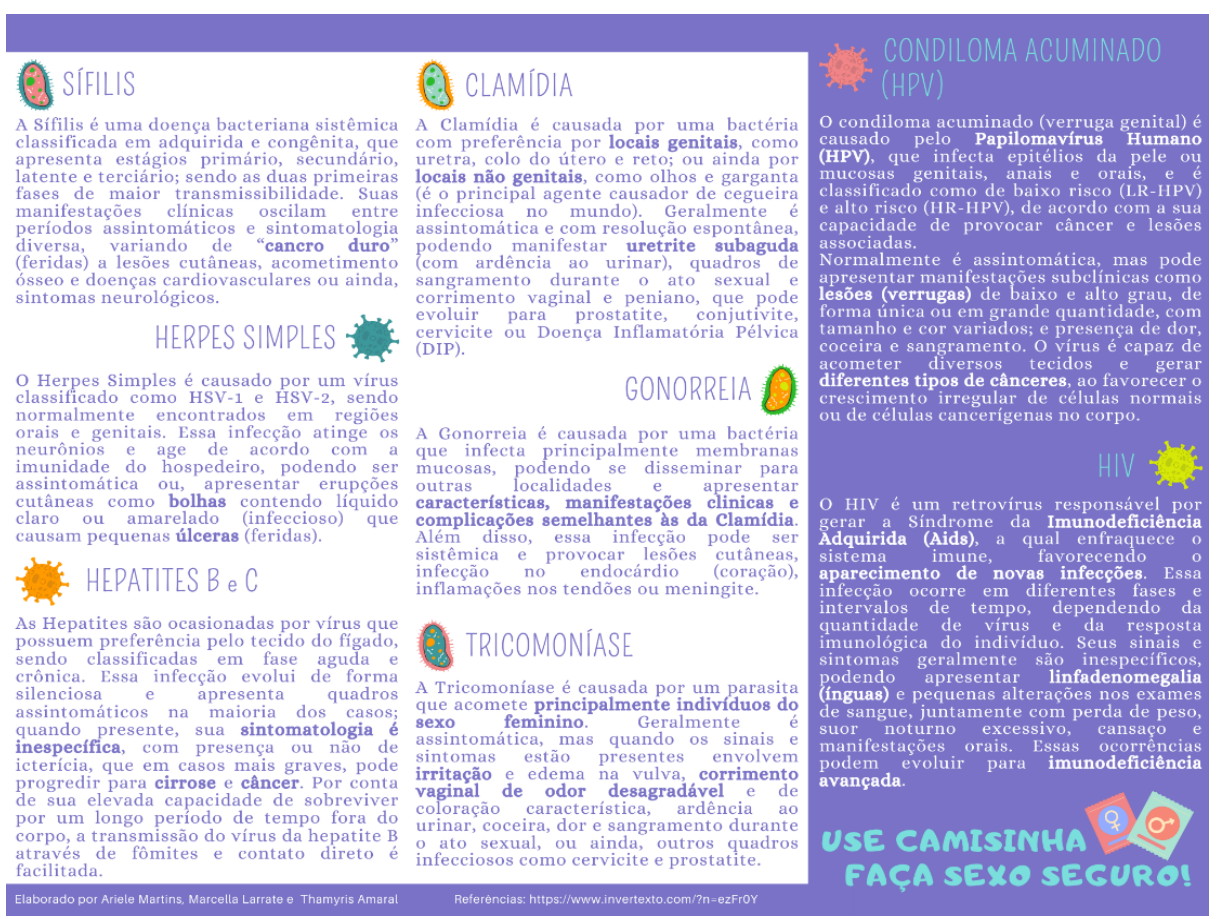

Fonte: Autores (2021). 


\section{Desenvolvimento de ações interativas}

Esta etapa foi caracterizada pelo desenvolvimento de atividades lúdico-educativas denominadas "Jogo de Tabuleiro Humano", "Quiz Torta na Cara" e "Ida ao Posto de Saúde" que abordam perguntas e respostas sobre IST, a fim de estimular o raciocínio e facilitar o aprendizado. Estes jogos devem ser realizados com ao menos 1 jogador representando cada grupo, alternando-os a cada rodada do jogo.

O Jogo de Tabuleiro Humano, ilustrado na Figura 4, deve possuir tamanho real e ser montado no chão, de forma que os participantes utilizem o próprio corpo como peça do jogo. As posições deverão ser avançadas até chegar ao final do tabuleiro e recomenda-se que tenham em média 20 casas para dispor de bom aproveitamento da dinâmica, uma vez que, ao longo do trajeto, o competidor terá que responder corretamente perguntas acerca do tema e obedecer aos comandos de avance/volte algumas casas.

O jogo se inicia com os jogadores posicionados na casa INÍCIO. Depois de acordado, o primeiro jogador lança o dado e avança o número indicado. $\mathrm{O}$ jogador deve responder de forma correta a pergunta referente à casa em que se encontra e, caso não o faça, deve voltar à casa INÍCIO e recomeçar. Algumas casas não são compostas por perguntas, assim, o jogador deve cumprir, quando existirem, os comandos indicados na posição em que se encontra. $\mathrm{O}$ vencedor será o primeiro a chegar na casa FIM. Este jogo pode ser adaptado com ampliação das perguntas/respostas. No Quadro 1 descrevemos as perguntas e respostas com os comandos utilizados.

Figura 4: Representação ilustrativa do Jogo de Tabuleiro Humano.

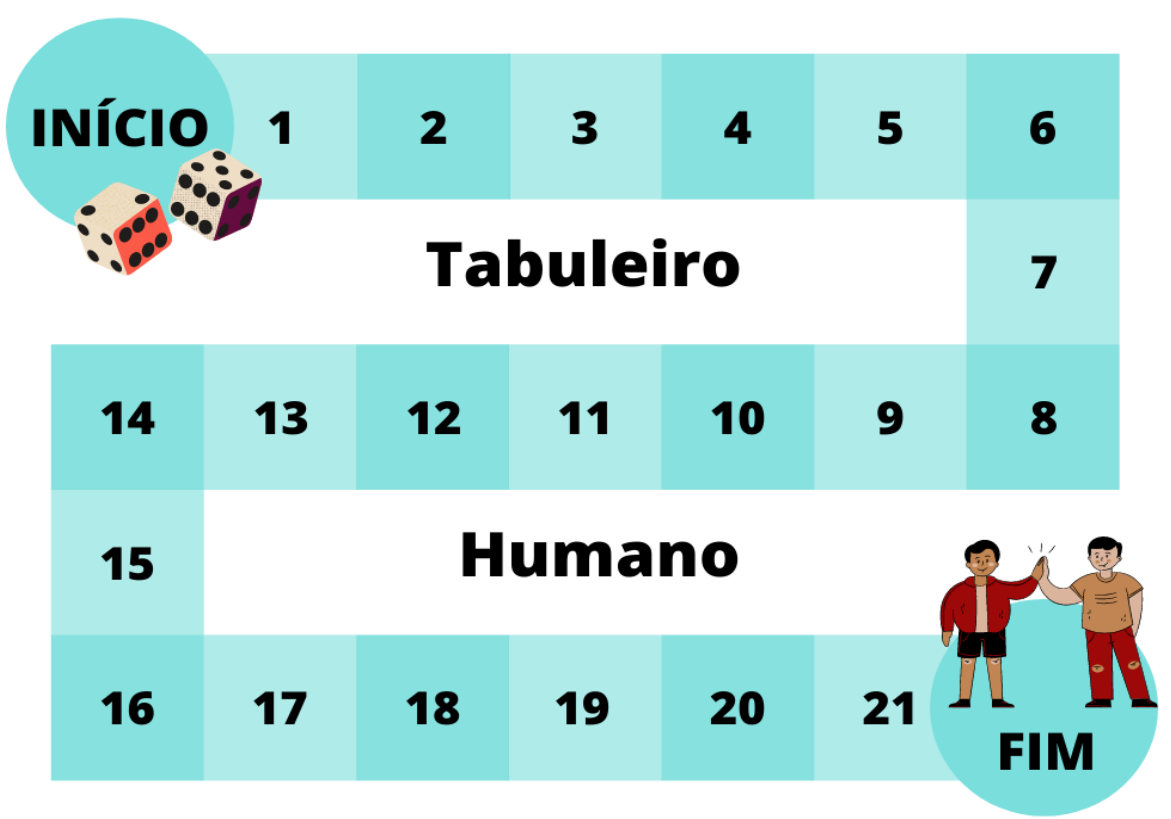

Fonte: Autores (2021). 
Quadro 1: Perguntas e Respostas referentes ao Jogo de Tabuleiro Humano.

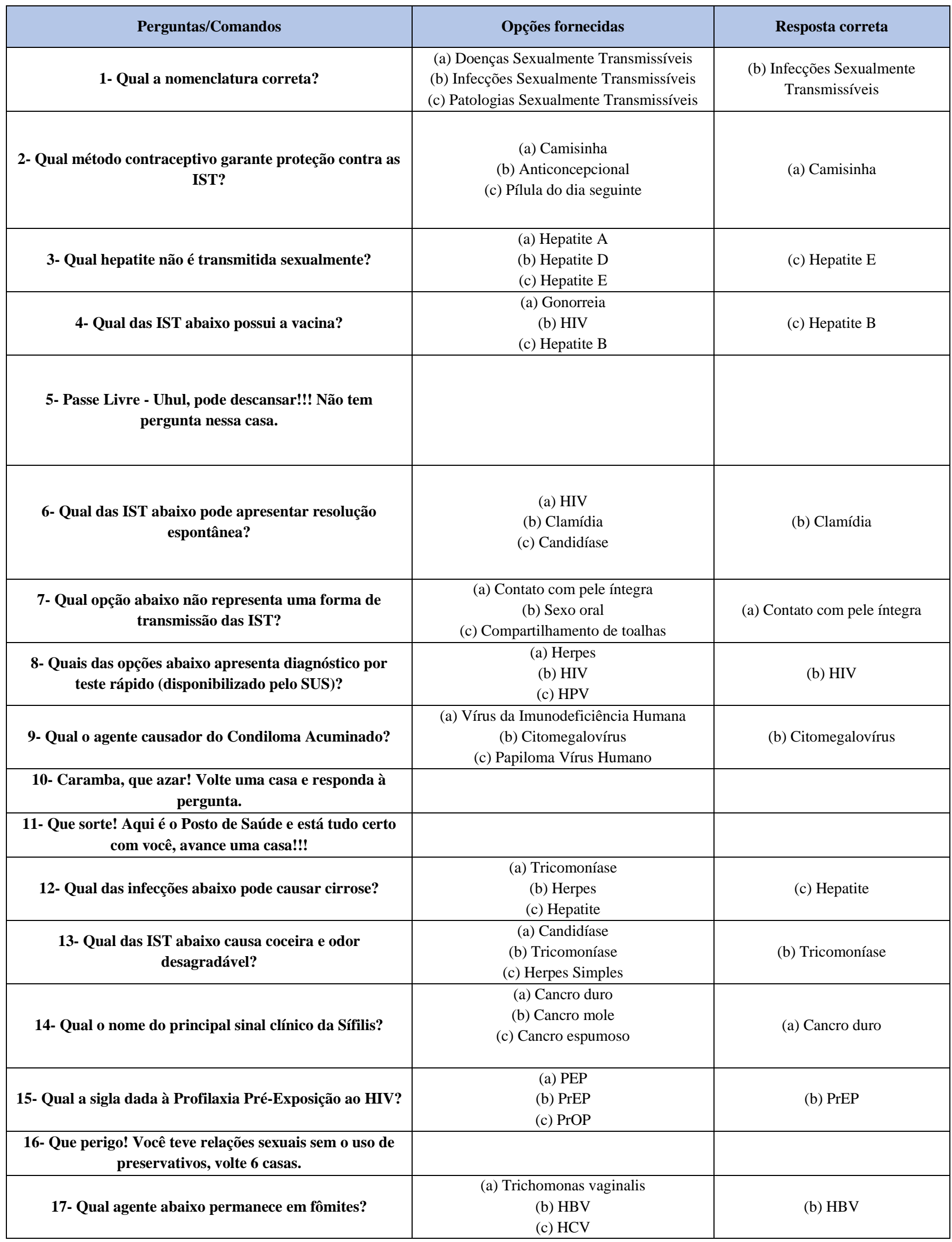




\begin{tabular}{|c|c|c|}
\hline $\begin{array}{l}\text { 18- Quantas camisinhas deve-se utilizar para uma maior } \\
\text { proteção? }\end{array}$ & $\begin{array}{l}\text { (a) } 1 \\
\text { (b) } 2 \\
\text { (c) } 3\end{array}$ & (a) 1 \\
\hline \multicolumn{3}{|l|}{$\begin{array}{c}\text { 19- Que vacilo! Você teve relação sexual sem camisinha } \\
\text { com um indivíduo infectado pelo HIV. Volte ao posto de } \\
\text { saúde e tome a sua PEP. }\end{array}$} \\
\hline $\begin{array}{l}\text { 20- Qual das IST abaixo é transmitida ao bebê durante a } \\
\text { gestação? }\end{array}$ & $\begin{array}{l}\text { (a) Herpes Simples } \\
\text { (b) Sífilis } \\
\text { (c) Condiloma Acuminado }\end{array}$ & (b) Sífilis \\
\hline $\begin{array}{l}\text { 21- Onde buscar ajuda para o diagnóstico e tratamento } \\
\text { das IST? }\end{array}$ & $\begin{array}{l}\text { (a) Corpo de Bombeiro } \\
\text { (b) SAMU } \\
\text { (c) Clínica da Família }\end{array}$ & (c) Clínica da Família \\
\hline
\end{tabular}

Fonte: Acervo Pessoal.

O Quiz Torta na Cara, por sua vez, consiste em um jogo de perguntas, descritas no Quadro 2, que diz se a informação dada é verdadeira ou falsa, e, em caso de resposta incorreta ou ausência de resposta, o jogador recebe uma "tortada" na cara. Recomenda-se, que para sua realização tenha-se uma estrutura de tamanho real posicionada na frente do participante, de forma que seja possível identificar qual jogador terá a oportunidade de responder, como mostra a Figura 5.

Para a execução dessa dinâmica, cada jogador deve se posicionar frente a frente. No centro haverá um dispositivo contendo o botão que sinaliza qual participante deverá responder à pergunta, com tempo máximo de resposta definido a critério do mediador. Em caso de acerto, o participante marca ponto e o adversário receberá a "tortada" na cara, confeccionada com chantilly, por exemplo. Caso o tempo de resposta seja excedido, o adversário terá a chance de responder à pergunta e, se também não o fizer, nenhum jogador será penalizado ou marcará ponto. Ganha o jogador que alcançar maior pontuação ao final do jogo. Em caso de empate, ocorrerá rodada extra e o primeiro jogador que responder corretamente vencerá.

Figura 5: Representação ilustrativa do Quiz Torta na Cara.

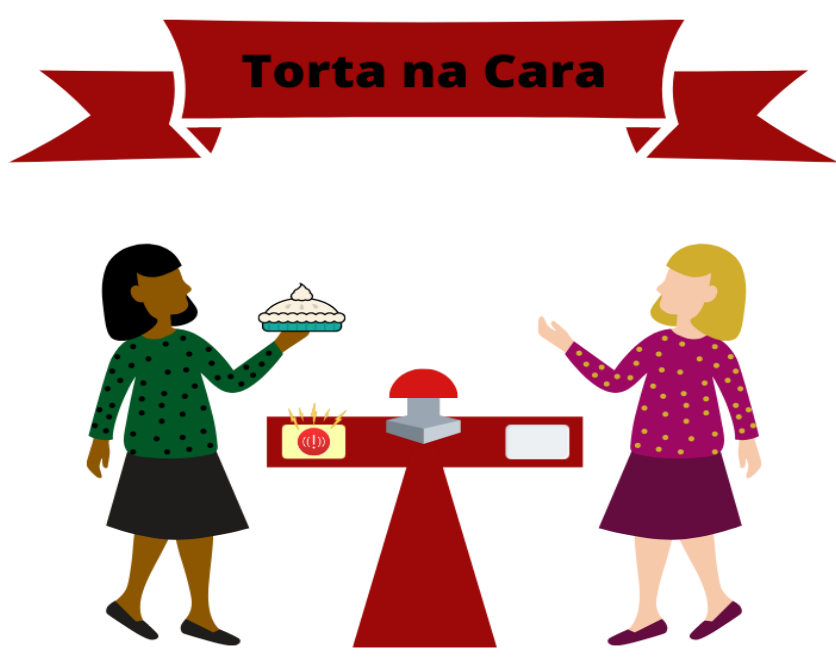

Fonte: Autores (2021). 
Quadro 2: Perguntas e Respostas referentes ao Quiz Torta na Cara.

\begin{tabular}{|c|c|c|}
\hline Perguntas/Comandos & Resposta Correta & Justificativa \\
\hline 1- O HIV é transmitido pelo beijo. & Falso & $\begin{array}{l}\text { O HIV não é transmitido pelo beijo, apenas por } \\
\text { contato sexual sem o uso de preservativos, } \\
\text { transmissão vertical ou uso compartilhado de } \\
\text { seringas e agulhas. }\end{array}$ \\
\hline $\begin{array}{l}\text { 2- O uso de camisinha feminina e masculina ao } \\
\text { mesmo tempo garante maior proteção. }\end{array}$ & Falso & $\begin{array}{l}\text { O uso de duas ou mais camisinhas não é } \\
\text { recomendado, pois aumenta o risco de rompimento } \\
\text { das mesmas. }\end{array}$ \\
\hline 3- A PrEP é usada antes da exposição ao HIV. & Verdadeiro & PrEP se refere a profilaxia pré-exposição. \\
\hline 4- O HPV pode causar câncer. & Verdadeiro & $\begin{array}{l}\text { Alguns sorotipos de HPV têm potencial } \\
\text { oncogênico. }\end{array}$ \\
\hline $\begin{array}{l}\text { 5- Infecções Sexualmente Transmissíveis podem } \\
\text { ser adquiridas pelo sexo oral. }\end{array}$ & Verdadeiro & $\begin{array}{l}\text { A transmissão das IST pode se dar por contato } \\
\text { sexual, via oral, vaginal ou anal. }\end{array}$ \\
\hline $\begin{array}{c}\text { 6- O vírus da Hepatite B não pode ser } \\
\text { transmitido por fômites (vaso sanitário) e } \\
\text { contato direto. }\end{array}$ & Falso & $\begin{array}{c}\text { O HBV pode ser transmitido dessas formas pois é } \\
\text { capaz de sobreviver por um longo período fora do } \\
\text { corpo. }\end{array}$ \\
\hline $\begin{array}{c}\text { 7- Existe vacina para HPV, HBV e Herpes } \\
\text { Simples. }\end{array}$ & Falso & $\begin{array}{c}\text { Não existe vacina para Herpes Simples, apenas } \\
\text { para HPV, HBV e HAV. }\end{array}$ \\
\hline 8- Verrugas são sinais característicos da Sífilis. & Falso & $\begin{array}{l}\text { As verrugas são características do HPV, enquanto a } \\
\text { sífilis é caracterizada pelo cancro duro. }\end{array}$ \\
\hline $\begin{array}{l}\text { 9- A Gonorreia e a Clamídia possuem sinais e } \\
\text { sintomas semelhantes. }\end{array}$ & Verdadeiro & $\begin{array}{l}\text { As manifestações clínicas de ambas são } \\
\text { semelhantes, incluindo principalmente uretrite. }\end{array}$ \\
\hline $\begin{array}{l}\text { 10- Os sinais e sintomas das IST aparecem } \\
\text { somente nos órgãos genitais. }\end{array}$ & Falso & $\begin{array}{l}\text { As manifestações clínicas das IST podem ocorrer } \\
\text { em outros locais do corpo como, por exemplo, na } \\
\text { boca. }\end{array}$ \\
\hline 11- Todas as IST apresentam sinais e sintomas. & Falso & $\begin{array}{l}\text { A maioria das IST se apresentam de forma } \\
\text { assintomática, principalmente em indivíduos do } \\
\text { sexo masculino. }\end{array}$ \\
\hline 12- A Herpes Simples tem cura. & Falso & $\begin{array}{l}\text { A infecção estabelece latência no corpo e pode ser } \\
\text { reativada por fatores externos. }\end{array}$ \\
\hline $\begin{array}{l}\text { 13- A tricomoníase acomete principalmente } \\
\text { mulheres. }\end{array}$ & Verdadeiro & $\begin{array}{l}\text { A tricomoníase se dá principalmente em mulheres, } \\
\text { com sintomatologia característica. }\end{array}$ \\
\hline $\begin{array}{l}\text { 14- A Hepatite } C \text { não é transmitida pelo mesmo } \\
\text { vírus da Hepatite } B \text {. }\end{array}$ & Verdadeiro & $\begin{array}{l}\text { A Hepatite C é causada por um vírus de RNA, } \\
\text { enquanto a Hepatite B por um vírus de DNA. }\end{array}$ \\
\hline 15- Candidíase é uma IST. & Falso & $\begin{array}{l}\text { A candidíase não é considerada uma IST, já que é } \\
\text { ocasionada por um fungo oportunista. }\end{array}$ \\
\hline
\end{tabular}

Fonte: Acervo Pessoal.

Como última proposta de jogo, o Ida ao Posto de Saúde refere-se à seleção de itens pelos participantes, respeitando os comandos de cada rodada e atentando-se às respostas corretas, visto que serão expostas opções pertinentes ou não à situação. As alternativas referentes às perguntas deverão ser escolhidas pelo participante e entregues ao mediador da dinâmica que, em caso de erratas, deverá instruir e justificar o porquê da alternativa incorreta.

Nessa prática, os jogadores devem se posicionar ao lado do mediador da dinâmica e decidir quem jogará primeiro. O primeiro jogador deve ir ao local "Posto de Saúde" e escolher as alternativas corretas relacionadas às perguntas em um tempo definido a critério do mediador. O vencedor será o que selecionar o maior número de respostas corretas às perguntas realizadas na rodada dentro do tempo definido. Em caso de empate, será realizada uma rodada extra e aquele que tiver maior pontuação será o vencedor. Na Figura 6 e no Quadro 3 encontram-se, respectivamente, a representação do jogo e as perguntas e respostas referentes às suas rodadas. 
Figura 6: Representação ilustrativa da dinâmica Ida ao Posto de Saúde.

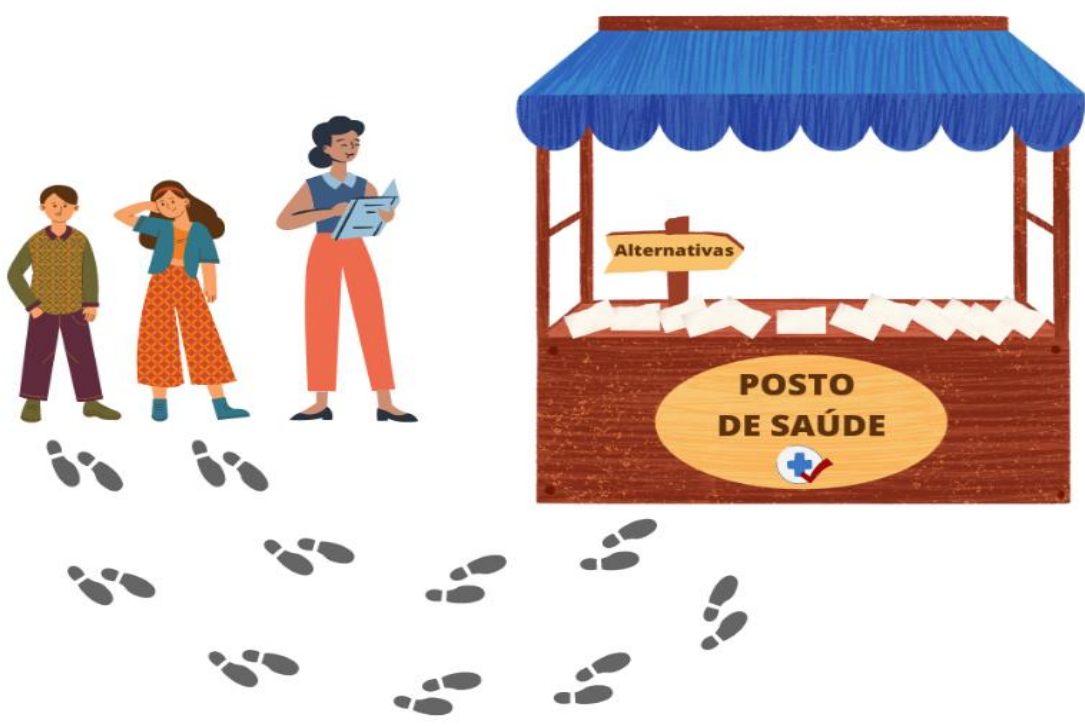

Fonte: Acervo Pessoal.

Quadro 3: Perguntas e Respostas referentes à dinâmica Ida ao Posto de Saúde.

\begin{tabular}{|c|c|c|}
\hline Perguntas/Comandos & Opções fornecidas & Resposta correta \\
\hline Rodada 1: Quais são as IST? & $\begin{array}{c}\text { Sífilis } \\
\text { Dengue } \\
\text { Hepatite B } \\
\text { Tuberculose } \\
\text { Hepatite C } \\
\text { Sarampo } \\
\text { HIV } \\
\text { Covid-19 } \\
\text { Herpes simples } \\
\text { Tétano } \\
\text { HPV } \\
\text { Doença de Chagas } \\
\text { Gonorreia } \\
\text { Verminoses } \\
\text { Tricomoníase } \\
\text { Poliomielite } \\
\text { Clamídia }\end{array}$ & $\begin{array}{c}\text { Sífilis } \\
\text { Hepatite B } \\
\text { Hepatite C } \\
\text { HIV } \\
\text { Herpes simples } \\
\text { HPV } \\
\text { Gonorreia } \\
\text { Tricomoníase } \\
\text { Clamídia }\end{array}$ \\
\hline Rodada 2: Prevenção para redução de danos & $\begin{array}{c}\text { PrEP } \\
\text { Lubrificante } \\
\text { Camisinha } \\
\text { Pílula anticoncepcional } \\
\text { PEP } \\
\text { Coito interrompido } \\
\text { Vacinação } \\
\text { Pílula do dia seguinte } \\
\text { Exame Papanicolau } \\
\text { Tabelinha } \\
\text { Testagem regular } \\
\text { Tratamento dos já infectados } \\
\text { Lavar as mãos } \\
\text { Não compartilhamento de objetos pessoais } \\
\text { Sexo durante o período menstrual }\end{array}$ & $\begin{array}{c}\text { PrEP } \\
\text { Camisinha } \\
\text { PEP } \\
\text { Vacinação } \\
\text { Exame Papanicolau } \\
\text { Testagem regular } \\
\text { Tratamento dos já infectados } \\
\text { Não compartilhamento de objetos } \\
\text { pessoais }\end{array}$ \\
\hline Rodada 3: Formas de transmissão & $\begin{array}{c}\text { Picada de mosquito } \\
\text { Contato sexual via oral } \\
\text { Contato com a pele íntegra } \\
\text { Contato sexual via anal } \\
\text { Beijo* }\end{array}$ & $\begin{array}{l}\text { Contato sexual via oral } \\
\text { Contato sexual via anal } \\
\text { Beijo* } \\
\text { Uso compartilhado de objetos } \\
\text { pessoais }\end{array}$ \\
\hline
\end{tabular}




\begin{tabular}{|c|c|c|}
\hline & $\begin{array}{c}\text { Uso compartilhado de objetos pessoais } \\
\text { Suor } \\
\text { Contato sexual vaginal } \\
\text { Abraços } \\
\text { Contato com a pele lesionada } \\
\text { Lágrima } \\
\text { Transmissão vertical } \\
\text { Espirros } \\
\text { Fômites* } \\
\end{array}$ & $\begin{array}{c}\text { Contato sexual vaginal } \\
\text { Contato com a pele lesionada } \\
\text { Transmissão vertical } \\
\text { Fômites* }\end{array}$ \\
\hline Rodada 4: Quais as IST curáveis? & $\begin{array}{c}\text { Sífilis } \\
\text { Hepatite B } \\
\text { Hepatite C } \\
\text { HIV } \\
\text { Herpes Simples } \\
\text { HPV } \\
\text { Gonorreia } \\
\text { Tricomoníase } \\
\text { Clamídia }\end{array}$ & $\begin{array}{c}\text { Sífilis } \\
\text { Hepatite C } \\
\text { Gonorreia } \\
\text { Tricomoníase } \\
\text { Clamídia }\end{array}$ \\
\hline Rodada 5: Quais as IST não curáveis? & $\begin{array}{c}\text { Sífilis } \\
\text { Hepatite B } \\
\text { Hepatite C } \\
\text { HIV } \\
\text { Herpes simples } \\
\text { HPV } \\
\text { Gonorreia } \\
\text { Tricomoníase } \\
\text { Clamídia }\end{array}$ & $\begin{array}{c}\text { Hepatite B } \\
\text { HIV } \\
\text { Herpes simples } \\
\text { HPV }\end{array}$ \\
\hline Rodada 6: Quais IST possuem vacina? & $\begin{array}{c}\text { Sífilis } \\
\text { Hepatite B } \\
\text { Hepatite C } \\
\text { Hepatite A } \\
\text { HIV } \\
\text { Herpes simples } \\
\text { HPV } \\
\text { Gonorreia } \\
\text { Tricomoníase } \\
\text { Clamídia }\end{array}$ & $\begin{array}{l}\text { Hepatite B } \\
\text { Hepatite A } \\
\text { HPV }\end{array}$ \\
\hline
\end{tabular}

*apenas em algumas IST. Fonte: Acervo Pessoal.

\section{Divulgação das Unidades de Atenção Primária à Saúde no território}

Os panfletos explicativos com o $Q R$ code contendo informações referentes às unidades de saúde serão entregues aos alunos presentes e ficarão disponíveis em ambiente de livre circulação para que os mesmos as acessem por meio de equipamento eletrônico. O QR code direcionará o estudante a um site governamental onde é possível obter informações acerca da localização e contato de unidades próximas.

O encerramento da ação de divulgação se dará com a premiação de participação e maiores acertos, que também deverá ter caráter lúdico. Espera-se ainda como etapa final, avaliar as percepções e impressões dos participantes sobre as atividades desenvolvidas.

Para a compreensão do ensino científico, alguns autores argumentam a importância das atividades lúdicas como recursos de cognição e ensino atrativos e criativos capazes de expandir o conhecimento e o desenvolvimento de habilidades, incentivando diferentes áreas de aprendizagem (Gritti \& Vieira, 2014; Campos et al., 2003). Assim, jogos no formato gincana estimulam a competitividade, participação e trabalho em equipe de estudantes envolvidos, além de operar como instrumentos capazes de instituir regras, auxiliar e incentivar o desenvolvimento da consciência (Tezani, 2006).

No estudo de Santos et al. (2020), a divulgação científica foi avaliada pela utilização de questionários destinados ao público-alvo (grupo de intervenção) - e grupo controle (sem intervenção). Os resultados estatísticos evidenciaram que o grupo de intervenção teve média de desempenho superior quando comparado ao grupo controle. 
Outra experiência exitosa utilizando a divulgação científica foi o estudo desenvolvido por Vicentino e Sant'Ana (2011) através de seu jogo intitulado "Trilha do Sistema Digestório", ao verificar que o modelo escolhido ampliou a aceitabilidade e a participação do público-alvo, promovendo a interação professor-estudante e estudante-estudante e tornando o processo de aprendizado mais divertido. Melo e colaboradores (2007) também identificaram resultados positivos acerca da implementação de atividades lúdicas para a difusão de conhecimento ao incitar o interesse e clarificar a assimilação do público abordado pelos autores frente ao tema científico referido.

Os estudos de Silva e colaboradores (2016) e Souza (2016), demonstraram a colaboração dos jogos didáticos no processo de ensino e aprendizagem ao retratar temas associados à divulgação científica de modo mais dinâmico e agradável. A eficácia dessas atividades como promotoras de informações foi relatada pelo público jovem, evidenciando a necessidade de sua inclusão como metodologia de ensino, proporcionando maior aprendizado, esclarecimento de dúvidas e redução de dispersões quando comparado a aulas formais; além de facilitar a aquisição e fixação de informações, a socialização, o trabalho em equipe e a cooperação entre os estudantes.

Assim, a divulgação científica pode atuar como ferramenta essencial para a democratização da informação e agir como influenciador nos indicadores de prevalência e incidência das IST, e ainda contribuir para a qualidade de vida e longevidade da população (Di Giulio, 2006).

\section{Considerações Finais}

O desenvolvimento de jogos e outras dinâmicas têm se mostrado adequado a adolescentes e jovens, possibilitando sua inclusão no mundo científico e obtenção de conhecimento de forma mais atrativa. Além disso, ilustra-se a relevância da introdução de práticas lúdico-educativas em conjunto às atividades tradicionais já executadas no contexto de sala de aula.

Apesar de sua importância, a temática acerca das Infecções Sexualmente Transmissíveis é pouco debatida, em parte devido ao grande tabu social relacionado ao conteúdo. Isto pode ocasionar um déficit sobre a educação sexual nas escolas e, consequentemente, em seus estudantes. Diante desse cenário, considera-se a divulgação científica como ferramenta de desenvolvimento social capaz de ultrapassar barreiras acadêmicas e operar como estratégia de ensino-aprendizagem, aumentando o desempenho e entendimento dos estudantes quanto ao tema.

Espera-se que essa proposta subsidie o desenvolvimento de educação em saúde no âmbito escolar, contribuindo para práticas pedagógicas mais condizentes às necessidades sociais e cognitivas deste grupo; e sugere-se que trabalhos futuros sejam realizados com aplicação desta proposta e adaptação a outras faixas etárias, promovendo uma divulgação científica mais ampla e eficaz. Recomenda-se que sejam realizados estudos que avaliem a recepção desta proposta pelos docentes e participantes envolvidos. Além disso, esta proposta pode ser aplicada como uma prática de caráter extensionista na comunidade científicoacadêmica, e desta forma contribuir para a formação de futuros profissionais de saúde mais capacitados e comprometidos socialmente.

\section{Referências}

Ahari, S. B., Moghadam, Z. B., Azin, S. A., \& Maasoumi, R. (2020). Concerns and educational needs of Iranian parents regarding the sexual health of their male adolescents: a qualitative study. Reproductive health, 17(1), 1-9.

Albagli, S. (1996). Divulgação científica: informação científica para cidadania. Ciência da informação, 25(3).

Almeida, R. A. A. S., Corrêa, R. D. G. C. F., Rolim, I. L. T. P., Hora, J. M. D., Linard, A. G., Coutinho, N. P. S., \& Oliveira, P. D. S. (2017). Conhecimento de adolescentes relacionados às doenças sexualmente transmissíveis e gravidez. Revista Brasileira de Enfermagem, 70, 1033-1039.

Amoras, B. C., Campos, A. R., \& Beserra, E. P. (2015). Reflexões sobre vulnerabilidade dos adolescentes a infecções sexualmente transmissíveis. PRACS: Revista Eletrônica de Humanidades do Curso de Ciências Sociais da UNIFAP, 8(1), 163-171. 
Andrade, F. C., de Freitas, W. C., \& da Silva Triani, F. (2019). O uso do game show passa ou repassa como metodologia ativa para o fomento do lúdico: Um relato de experiência. Revista Valore, 4, 107-118.

Barreto, R. M. A., Santos, R. B., Bezerra, A. C. L., \& Silva, M. A. M. (2016). IST na adolescência: percepção de gestantes à luz do círculo de cultura de paulo freire. Revista Contexto \& Saúde, 16(30), 116-125.

Campos, L. M. L., Bortoloto, T. M., \& Felício, A. K. C. (2003). A produção de jogos didáticos para o ensino de ciências e biologia: uma proposta para favorecer a aprendizagem. Caderno dos núcleos de Ensino, 47, 47-60.

Carloto, C. M., \& Damião, N. A. (2018). Direitos reprodutivos, aborto e Serviço Social. Serviço Social \& Sociedade, $306-325$

Casseb, T. F., do Nascimento, L. S., Matos, P. B. L., de Nazaré Lopes, A. L., Lucas, A. C. M., Pires, M. J. M., \& dos Santos, I. O. (2020). O jogo “remo da saúde bucal" como ferramenta para educação em saúde bucal. Revista Eletrônica Acervo Saúde, (50), e3458-e3458.

Castro, E. L., Caldas, T. A., Morcillo, A. M., Pereira, E. D. A., \& Velho, P. E. N. F. (2016). Awareness and education regarding sexually transmitted diseases among undergraduate students. Ciencia e Saúde Coletiva.

Cejam. (2021). Infecções sexualmente transmissíveis (IST); saiba o que são e como se proteger. https://cejam.org.br/noticias/infeccoes-sexualmentetransmissiveis-ist-saiba-o-que-sao-e-como-se-proteger

Costa, M. I. F. D., Viana, T. R. F., Pinheiro, P. N. D. C., Cardoso, M. V. L. M. L., Barbosa, L. P., \& Luna, I. T. (2019). Determinantes sociais de saúde e vulnerabilidades às infecções sexualmente transmissíveis em adolescentes. Revista Brasileira de Enfermagem, 72, $1595-1601$.

Cruz, M. M. D. (2006). Avaliação de programas de prevenção de DST/AIDS para jovens: estudo de caso numa organização governamental e numa organização não-governamental do município do Rio de Janeiro (Tese de Doutorado). Fundação Oswaldo Cruz, Rio de Janeiro, RJ

Cyrino, E. G., \& Toralles-Pereira, M. L. (2004). Trabalhando com estratégias de ensino-aprendizado por descoberta na área da saúde: a problematização e a aprendizagem baseada em problemas. Cadernos de Saúde Pública, 20, 780-788.

Departamento de Doenças de Condições Crônicas e Infecções Sexualmente Transmissíveis. (2017). Boletim epidemiológico HIV/Aids 2017. http://www.aids.gov.br/pt-br/pub/2017/boletim-epidemiologico-hivaids-2017

Departamento de Doenças de Condições Crônicas e Infecções Sexualmente Transmissíveis. (2020). Boletins epidemiológico - Linha do tempo. http://www.aids.gov.br/pt-br/centrais-de-conteudos/boletins-epidemiologicos-vertical

Departamento de Doenças de Condições Crônicas e Infecções Sexualmente Transmissíveis. Infecções Sexualmente Transmissíveis. http://www.aids.gov.br/ptbr/publico-geral/o-que-sao-ist

Departamento de Promoção da Saúde. (2021). Programa Saúde na Escola; FAQ (perguntas frequentes). http://189.28.128.100/dab/docs/portaldab/documentos/pse/FAQ_PSE.pdf

Di Giulio, G. M. (2006). Divulgação científica e comunicação de risco: um olhar sobre Adrianópolis, Vale do Ribeira.

Doreto, D. T., \& Vieira, E. M. (2007). O conhecimento sobre doenças sexualmente transmissíveis entre adolescentes de baixa renda em Ribeirão Preto, São Paulo, Brasil. Cadernos de Saúde Pública, 23(10), 2511-2516.

Fernandes, A. M. D. S., Antonio, D. D. G., Bahamondes, L. G., \& Cupertino, C. V. (2000). Conhecimento, atitudes e práticas de mulheres brasileiras atendidas pela rede básica de saúde com relação às doenças de transmissão sexual. Cadernos de Saúde Pública, 16, S103-S112.

Fernandes, F (2020). A educação para sexualidade nos anos iniciais. (Dissertação de Mestrado). Universidade Federal do Paraná, Curitiba, PR.

Figueiredo, R. S., Zambom, A. C., \& Saito, J. (2001). A introdução da simulação como ferramenta de ensino e aprendizagem. Enegep (Encontro Nacional de Engenharia de Produção), Salvador, Bahia.

Freire, A. L., Araújo, K. S. D., Vila, A. C. D., \& Araújo, M. A. D. S. (2016). Assistência de enfermagem à mulher no climatério e sua sexualidade: relato de experiência na atenção básica. Revista De Trabalhos Acadêmicos-Universo-Goiânia.

Graciano, A. M. C, Cardoso, N. M. M., Mattos, F. F., Gomes, V. E., \& Borges-Oliveira, A. C. (2015). Promoção da Saúde na Escola: história e perspectivas. Journal of Health \& Biological Sciences, 3(1), 34-38.

Gritti, A., \& Vieira, A. (2014). Jogos didáticos no ensino de ciências do $6^{\circ}$ ano. PARANÁ. Secretaria de Estado da Educação. Superintendência de Educação. Os Desafios da Escola Pública Paranaense na Perspectiva do Professor PDE: Produção Didático-pedagógica.

Meirelles, R. M. S. D., Ferreira, C. P., Costa, E. C. P., \& Oliveira, M. D. F. A. D. (2017). Jogo sobre educação em saúde: limites e possibilidades. Eseñanza de Las Ciencias, n. ${ }^{\circ}$ extraordinario: 5079-5084.

Melo, D. J., Bastos, A. C. F., Rodrigues, V. M. C., \& Monção, V. M. (2007). Desenvolvimento de atividade lúdica para o auxílio do ensino e divulgação científica da paleontologia. Anuário do Instituto de Geociências, 30(1), 73-76.

Miranda, V., Nascimento, L., Sampaio, G., Nascimento, P., Silva, Y., Ramos, B., Freitas, Y. \& Branco, C. W. C. (2020). As novas tecnologias na popularização da ciência: projeto tecalajes e a divulgação científica de amebas testáceas (amorphea, amoebozoa). In IV Seminário Nacional de Integração da Rede PROFCIAMB 2020 .

Mitre, S. M., Siqueira-Batista, R., Girardi-de-Mendonça, J. M., Morais-Pinto, N. M. D., Meirelles, C. D. A. B., Pinto-Porto, C., \& Hoffmann, L. M. A. (2008). Metodologias ativas de ensino-aprendizagem na formação profissional em saúde: debates atuais. Ciência \& saúde coletiva, 13, $2133-2144$. 
Research, Society and Development, v. 11, n. 2, e24711225598, 2022

(CC BY 4.0) | ISSN 2525-3409 | DOI: http://dx.doi.org/10.33448/rsd-v11i2.25598

Organización Mundial de la Salud. (2016). Estrategia Mundial del sector de la salud contra las Infecciones de Transmisión Sexual 20162021. http://apps.who.int/iris/bitstream/handle/10665/250253/;jsessionid=6DFD642122CE9CC2058C47C097CCEA60?sequence=1

Pedroso, C. V. (2009). Jogos didáticos no ensino de biologia: uma proposta metodológica baseada em módulo didático. In Congresso Nacional de Educação. 9 , 3182-3190

Pereira, R. J. B., Azevedo, M. M. R., Sousa, E. T. F., \& Hage, A. X. (2020). Método tradicional e estratégias lúdicas no ensino de Biologia para alunos de escola rural do município de Santarém-PA. Experiências em Ensino de Ciências, 15(02), 106-123.

Ramos, D. B. D. N., Burlandy, L., Dias, P. C., Henriques, P., Castro, L. M. C., Teixeira, M. R. M., \& Cruz, M. C. C. (2020). Propostas governamentais brasileiras de ações de prevenção e controle do sobrepeso e obesidade sob perspectiva municipal. Cadernos de Saúde Pública, 36.

Santos, L. B., Zednik, H., \& Soares, S. M. N. A. (2020). Divulgação científica: Qual a eficiência desta ferramenta no ensino? Uma análise utilizando a Teoria da Evolução Biológica. Educação Contemporânea-Volume 17 Reflexões, 21.

Santos, S. M. P. D., Freitas, J. L. G. D. S., \& Freitas, M. I. D. F. (2019). Roteiros de sexualidade construídos por enfermeiros e a interface com a atenção em infecções sexualmente transmissíveis/HIV. Escola Anna Nery, 23.

Shannon, C. L., \& Klausner, J. D. (2018). The growing epidemic of sexually transmitted infections in adolescents: a neglected population. Current opinion in pediatrics, 30(1), 137.

Silva, N. M. A., Dias, M. A. S., Araújo, D. F. S., \& Pereira, J. M. (2016). Relato de experiência didática sobre o uso dos jogos na construção da aprendizagem dos conteúdos de biologia.

Sousa, R. F. V. D. (2020). Infecções sexualmente transmissíveis: percepção de adolescentes e jovens em uma instituição de ensino público de referência no estado do Piauí (Dissertação de Mestrado). Fundação Oswaldo Cruz, Teresina, PI.

Souza, C. D. S., Iglesias, A. G., \& Pazin-Filho, A. (2014). Estratégias inovadoras para métodos de ensino tradicionais: aspectos gerais. Medicina (Ribeiräo Preto), 284-292.

Souza, J. S. (2016). Experimentação com materiais alternativos aliada ao jogo: uma proposta para a divulgação científica em comunidades ribeirinhas no baixo rio branco-roraima (Dissertação de Mestrado). Universidade Federal de Roraima, Boa Vista, PR

Tezani, T. C. R. (2006). O jogo e os processos de aprendizagem e desenvolvimento: aspectos cognitivos e afetivos. Educação em revista, 7(1-2), 1-16.

Vasconcellos, M. S., de Carvalho, F. G., Barreto, J. O., \& Atella, G. C. (2017). As Várias Faces dos Jogos Digitais na Educação. Informática na educação: teoria \& prática, 20(4).

Vicentino, S. L., \& Sant'ana, D. D. M. G. (2011). A Divulgação Científica por meio de um jogo: trilha do Sistema Digestório. Arquivos do MUDI, 15(1/2/3), 17 .

World Health Organization. (2019). Sexually transmitted infections (STIs). https://www.who.int/news-room/fact-sheets/detail/sexually-transmitted-infections(stis) 